\title{
Health-Related Rehabilitation after the 2008 Great Wenchuan Earthquake in China: A Ten Year Retrospective Systematic Review
}

\author{
Joseph Kimuli Balikuddembe ${ }^{1, *(1)}$, Xinglin Zeng ${ }^{2}$ and Chuandong Chen ${ }^{1,3}$ \\ 1 Institute for Disaster Management and Reconstruction, Sichuan University and Hong-Kong Polytechnic \\ University, Chengdu 610000, China; leochancd@163.com \\ 2 Rehabilitation Department, West China School of Medicine, Sichuan University, Chengdu 610000, China; \\ 2016141624073@stu.scu.edu.cn \\ 3 West China School of Public Health, Sichuan University, Chengdu 610000, China \\ * Correspondence: jbalikuddembe.k@scu.edu.cn
}

Received: 18 January 2020; Accepted: 27 March 2020; Published: 29 March 2020

\begin{abstract}
Being one of the world's seismically hazard-prone countries, the People's Republic of China (PRC) witnessed an 8.0-magnitude earthquake on May 12th 2008-which was reported as one of the most destructive disasters since its founding. Following this earthquake, rehabilitation was greatly required for survivors to enable them to achieve and maintain optimal independence; functioning; full physical, mental and social ability; inclusion; and participation in all aspects of life and environments. We conducted a systematic review based on Preferred Reporting Items for Systematic Reviews and Meta-Analyses (PRISMA) guidelines to retrospectively identify, in five English databases/sources, the existing evidence about the Health-Related Rehabilitation (HRR) that was rendered to the survivors of the 2008 Wenchuan earthquake between 2008 and 2018. Only 11 studies out of 828 initial studies retrieved were included in our study and reported the survivors of the 2008 Wenchuan earthquake to have been aged between 10.5 and 55.7, and predominantly diagnosed with posttraumatic stress disorders. Their HRR was mainly premised on physical and physiological therapies, as well as traditional Chinese medicine and digital technologies. Although all HRR interventions used were reported to be effective, none was identified as much more effective than the others in the post-earthquake era - which calls for more robust research to build upon our systematic review.
\end{abstract}

Keywords: health-related rehabilitation; Wenchuan; Sichuan; earthquake; China; systematic review

\section{Introduction}

The People's Republic of China (PRC) is one of the most seismic hazard-prone countries in the world given its location at the junction of the circum-Pacific seismic belt and the Mediterranean Himalayan seismic belt [1]. As a result, the country has a historical legacy of fatal earthquakes which have stuck with it over the last 100 years [2-4]. Almost all types of natural disaster have been reported in China with the exception of volcanic eruptions [1], including-among others-floods, droughts, landslides, mudslides and typhoons [1,4-6]. China's proneness to disasters is attributed to its vast territory, various climatic zones, complex geographical environment and fragile ecological conditions [7]. With respect to earthquakes, the western and eastern parts of PRC are reported to be the most earthquake-prone areas. Accordingly, earthquakes constitute one of the most deadly types of natural disaster, associated with adverse impacts whenever they occur in terms of mass fatalities, injuries, disabilities, morbidity, displacement, posttraumatic stress disorders (PTSD), extensive property damage and devastating economic losses [2,6,8-14]. On the afternoon of May 12th 2008, the earthquake of 8.0-magnitude (Mw) 
on the Richter scale, that was reported as one of the most destructive disasters since the founding of PRC, majorly struck Wenchuan country-located in Sichuan Province, a mountainous region in the Southwest of China $[3,4,9,10,14,15]$. The death toll due to this earthquake was estimated at over 87,000 , there were 18,618 missing persons and 374,000 injured, and it nearly left over 45 million people affected in one way another, for example, in terms of being traumatized, displaced and contracting various diseases $[4,6,9,10,16,17]$. On the other hand, the earthquake's total economic damage was estimated at over 8,451.0 hundred million Chinese Yuan (¥) [4].

Apart from disintegrating the family and social networks normally depended upon by people [18], disasters such as earthquakes also inhibit economical livelihoods, as well as the delivery of essential needs and services, for instance, healthcare, food, clean water, housing and education. This happens following the damage or destruction of essential infrastructure such as hospitals, buildings and roads, and water, electricity, gas and telecommunication facilities [4,6,8]. More so, earthquakes are known to be associated with high mortality, morbidity and disability rates, which are aggravated by the multiple and complex injuries they cause, for example, traumatic brain injury (TBI), spinal cord injury (SCI), fractures, crush injuries, penetrating wounds or soft wounds $[9,11,17,19]$. This situation was not exceptional with the 2008 Wenchuan earthquake-which, as mentioned above, contributed to over 374,000 injuries and other impacts [6,9]. Arguably, apart from the emotional and mental consequences, earthquake-induced injuries and disability affect the functional ability, independence and social participation of victims [20]. Dealing with a high number of injured individuals after earthquakes is challenging, and if they are inadequately and not timely identified for comprehensive diagnostics, emergency and formalized treatment [11], many avoidable deaths and life-changing disabilities among survivors can be caused. The challenge, however, is how the various needs of and services for victims related to health, economic, social and cultural aspects can be appropriately rendered and sustained in the long term, especially after the occurrence of large-scale earthquakes-which are known to overwhelm available resources.

Earthquakes not only increase the degree of vulnerability of individuals but also mean that the those who are injured or disabled, and victims with disabling health conditions, become dependents and become reliant on equipment and supplies, and their immediate families, governments and other providers. In this case, the victims require special attention to meet their essential needs, as well as extramural support to carry out their activities of daily living (ADL) such as walking, eating, bathing, dressing, toileting, transferring and others [21]. With this situation in mind, the role of rehabilitation cannot be emphasized enough to assist individuals who experience or are likely to experience disability after earthquakes, in order to achieve and maintain optimal independence; functioning; full physical, mental, social and vocational ability; and inclusion and participation in all aspects of life and environments [22,23]. Rehabilitation is emphasized not only as an essential component of development but also an inalienable human right to health. So far, this is delineated in the Universal Declaration of Human Rights [24], the 2030 Rehabilitation Agenda [25], the World Health Organization's Global Disability Action Plan (2014-2021) [26] and the United Nations Convention on the Rights of People with Disabilities (CRPD) [27]. Rehabilitation is usually provided by a mix of family, friends, community volunteers, and professionals or nonprofessional personnel, either in the community or in rehabilitation centers $[22,23,25,26,28]$.

Although it is now over ten years since the 2008 Wenchuan earthquake occurred, its devastating impacts continue to reverberate in the minds of the Sichuanese people, especially in the prefectures or counties of Wenchuan, Mianzhu, Qingchuan, Shifang, Dujiangyan, Beichuan and Qiang Autonomous County-where the majority of the causalities were witnessed $[4,16,20]$. Immediately after the 2008 Wenchuan earthquake struck and to date, the central and provincial governments of PRC and other stakeholders rapidly responded to the disaster by embarking on several post-earthquake interventions, including rehabilitation care, as reported in a substantive body of literature $[1,3-5,9,10,19]$. Ideally, planning for rehabilitation services for populations in the aftermath of earthquakes and others disasters is paramount to help to support not only the survivors with long-term disabilities and those living with 
different disabling conditions, but also those involved in the relief process, including the health-care workers [10]. Moreover, in the quest of achieving the Sendai Framework for Disaster Risk Reduction 2015-2030 — a global strategy for addressing disaster risk and resilience-the need for rehabilitation is recognized throughout [29]. Therefore, through a systematic review, the present study aimed at retrospectively identifying the existing evidence about the health-related rehabilitation that has been rendered to the victims or survivors of the 2008 Wenchuan earthquake between 2008 and 2018 . Ultimately, the findings of this study are intended to help to inform further interventions for effective rehabilitation services, particularly to the survivors of earthquakes with life-long disabling conditions, not limited only to those of the 2008 Wenchuan earthquake but also those of other earthquakes and disasters elsewhere.

\section{Materials and Methods}

\subsection{Study Design}

This review was conducted by following the Preferred Reporting Items for Systematic Reviews and Meta-Analyses (PRISMA) guidelines [30], to identify the existing evidence about the health-related rehabilitation (HRR) interventions which have been rendered to the survivors or victims of the 2008 Wenchuan earthquake between 2008 and 2018. We defined HRR based on Article 26 (Habilitation and Rehabilitation) of CRPD which outlines the measures States Parties should undertake to ensure that PWDs can access health-related rehabilitation... [Sic]...including through peer support, to enable them to attain and maintain their maximum independence; full physical, mental, social and vocational abilities; and full inclusion and participation in all aspects of life [23]. HRR is diverse in terms of target population interventions (rehabilitation medicine, orthopaedic surgery, physiotherapy, speech and language therapy, occupational therapy and assistive devices) and outcomes.

\subsection{Inclusion and Exclusion Criteria}

The inclusion criteria of our systematic review focused on retrospectively identifying the studies of interest that reported the following: 1) injured survivors or victims (as the target population) who were negatively impacted in terms of physical, mental or psychological functioning, activity and participation limitation following the 2008 Wenchuan or 5.12 earthquake; 2) primary research studies (with original designs) that reported different HRR interventions or programs, for example, those based on physical, occupational and psychological therapies, traditional Chinese Medicine, education and non-Pharmaceutical therapy; 3) studies conducted within China, and with particular focus on the 2008 Wenchuan earthquake; and 4) studies published in English within the period between 2008 and 2018. We excluded studies based on the following: 1) with a scope and main focus not related to the 2008 Wenchuan earthquake; 2) without an original study design; 3) published before May 12th 2008 and after 2018; 4) not published in English; and 5) literature reviews, news pieces, editorials, narrative descriptions, opinions, commentaries, health policy or emergency response studies, pharmaceutical studies, surgical or rehabilitation studies, case reports, commentaries, letters to the editor, and conference proceedings.

\subsection{The Search Strategy}

Initially, based on the abovementioned inclusion criteria, three independent reviewers (JBK, ZX and LC) extracted the relevant studies or articles in five English databases/sources including PubMed, Science Direct, Springer Link, Web of Science and Google Scholar. The period between May 12th 2008 and after May 12th 2018 was considered since it marked the tenth (10th) anniversary of the 2008 Wenchuan earthquake. Following the PRISMA guidelines, the search strategy involved using a mix of MeSH keywords and free text terms as follows: ((((injuries) OR pain)) AND (((()((rehabilitation) OR physical therapy) OR occupational therapy) OR psychological therapy) OR education) OR 
non-Pharmaceutical therapy) OR traditional Chinese medicine)) AND (((Wenchuan earthquake) OR $5 \cdot 12$ earthquakes) OR Sichuan earthquake).

\subsection{The Data Abstraction Process}

At first, the search results were critically read based on their titles, abstracts and keywords. Their related information was abstracted using Microsoft Excel as follows: the title, the publication date of the study, the setting where the study was conducted, research questions/hypotheses, the study design, the population subtype/participants, the sample size, the intervention and the key findings or recommendations. This helped with the quick identification and screening of eligible studies meeting our study criteria. Afterwards, the full texts of studies identified eligible were retrieved and stored in an Excel Spreadsheet and in the EndNote software X8 (Thomson Reuters, Philadelphia, United States). At this stage, we identified and eliminated any duplicates found. The details of retrieved studies were categorized according to the five respective databases/sources from which they were retrieved, as well as the types of their designs, which mainly included cross-sectional, clinical, randomized controlled trial (RCT), case-control, data analysis and longitudinal designs. Additionally, the references of eligible studies were further explored for the purpose of identifying more potential and relevant studies that would have been missed in the initial search results.

\subsection{Screening and Study Selection}

Two reviewers (JBK and ZX) critically read and screened the searched studies based on their titles, abstracts and keywords before retrieving and storing their retrieved full texts in both a Microsoft Excel Spreadsheet and in the EndNote software X8, as noted above. Using the Population Intervention Comparison Outcome (PICO) method [31,32], details of the eligible studies were sub-grouped according to the following: the cities/hospital, the study design, interventions, the study purpose, the subject age/gender, the numbers of patients, the study type, primary outcomes and recommendations/primary findings of the study. Each article (study) was still reviewed independently by JBK and ZX, and in the case of any discrepancies emerging regarding their eligibility, the two reviewers resolved them by discussion. Regarding this, no case necessitated the intervention of a third reviewer. During this stage, the reliability and validity of each of the studies reviewed was ensured. At the end of the screening process, studies eligible for final inclusion in our systematic review were identified and also categorized either as RCT or non-RCT.

\subsection{Quality Assessment}

An analysis of the methodological quality was done by JBK and ZX to assess the risk of bias for all RCT studies retrieved using the Cochrane Collaboration's risk of bias tool [33]. This was aimed at assessing their risk of bias, rigor, and transparency. The Cochrane Collaboration's risk of bias tool contains seven items, namely random sequence generation (selection bias), allocation concealment (selection bias), the blinding of participants and personnel (performance bias), the blinding of outcome assessment (detection bias), incomplete outcome data (attrition bias), selective reporting (reporting bias) and other bias. All included studies were rated as having a low, unclear or high bias based on the seven items. Besides, we used the Risk of Bias in the Non-randomized Studies of Interventions (ROBINS-I tool, innovated at University of Bristol, Bristol, United Kingdom) [34] to assess the non-RCT studies for their quality. ROBINS-I is similarly based on the Cochrane Risk of Bias tool for RCTs and consists of seven domains: confounding, selection, departures from intended interventions, missing data, measurement of intervention, outcome measurement and selective reporting [33]. 


\section{Results}

\subsection{Search Results}

Initially, a total of 821 studies were electronically retrieved from the five English databases (Figure 1). An additional seven potentially relevant studies were also identified through searching the references of the 821 studies. As a result, this yielded a total of 828 records as eligible studies for screening in our systematic review. After conducting all of the relevant screening, including removing the duplicates, the full texts of only 11 studies finally met the inclusion criteria in line with the purpose of our systematic review. A summary of the characteristics of the 11 studies $[16,17,19,20,35-41]$ is presented in Table 1. The 11 studies were published between 2012 and 2019, the majority of them in 2013 [16,17,36] and 2014 [37-39], whereby three studies $(n=3)$ were published in each year. In this case, no study was retrieved that had been published in the immediate aftermath of the 2008 Wenchuan earthquake.
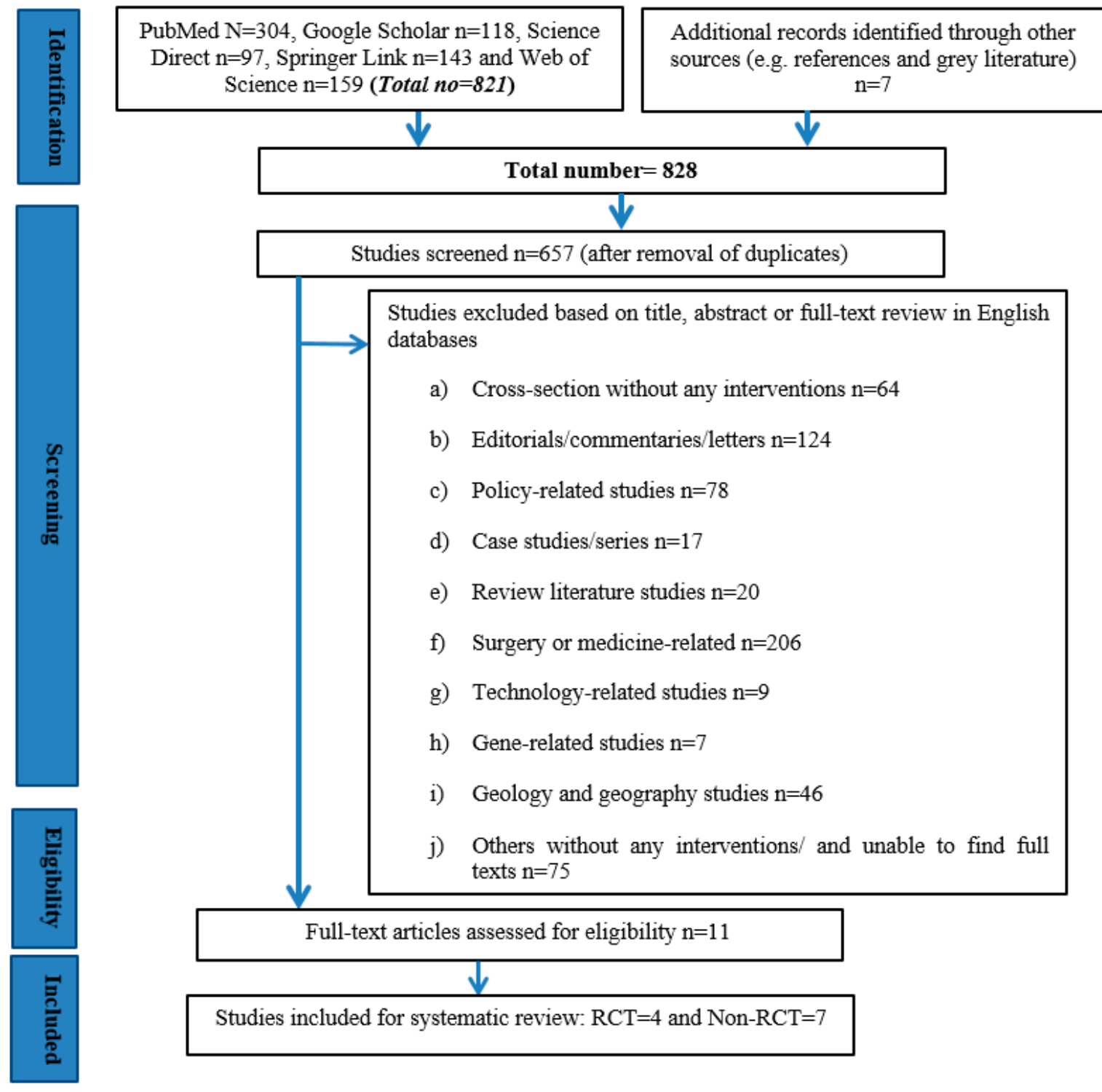

Figure 1. A flow chart indicating the processes that were involved in identifying, retrieving and screening the eligible studies for the systematic review, based on PRISMA. 
Table 1. Details of the final studies that were included in the systematic review.

\begin{tabular}{|c|c|c|c|c|c|c|c|c|}
\hline & Author/Year & Study Design & Study Objective(s)/Aim(s) & Intervention(s) & $\begin{array}{l}\text { Participant Inclusion } \\
\text { and Type of Subject }\end{array}$ & $\begin{array}{c}\text { Subject } \\
\text { Gender/Age }\end{array}$ & $\begin{array}{l}\text { Study Outcome } \\
\text { Measurement }\end{array}$ & $\begin{array}{c}\text { Recommendations/Primary } \\
\text { Findings }\end{array}$ \\
\hline 1 & $\begin{array}{l}\text { Zang Yinyin } \\
{[36] / 2013}\end{array}$ & $\mathrm{RCT}$ & $\begin{array}{l}\text { Evaluate the efficacy of } \\
\text { NET as a short-term } \\
\text { treatment for PTSD } \\
\text { earthquake survivors. }\end{array}$ & NET & 22/PTSD & $\begin{array}{c}\text { Male }=5 ; \\
\text { Female }=17 / \mathrm{E} \\
=56.64 \& \mathrm{C}= \\
54.82\end{array}$ & $\begin{array}{c}\text { PTSD symptoms, } \\
\text { general mental health, } \\
\text { social support, coping } \\
\text { style and } \\
\text { posttraumatic change }\end{array}$ & $\begin{array}{l}\text { Effectiveness in treating } \\
\text { post-earthquake traumatic } \\
\text { symptoms in adult Chinese } \\
\text { earthquake survivors }\end{array}$ \\
\hline 2 & $\begin{array}{l}\text { Ying Chen } \\
\text { [38]/ } 2014\end{array}$ & RCT & $\begin{array}{l}\text { Compared the treatment } \\
\text { effectiveness of short-term } \\
\text { CBT with a general } \\
\text { supportive intervention } \\
\text { and with a control group of } \\
\text { non-treatment. }\end{array}$ & CBT & 40/Adolescence & $\begin{array}{c}\text { Male }=13 \\
\text { Female }= \\
27 / \text { Age }=14.50\end{array}$ & $\begin{array}{l}\text { Psychological } \\
\text { resilience, PTSD \& } \\
\text { depression }\end{array}$ & $\begin{array}{l}\text { CBT was effective in } \\
\text { reducing PTSD and } \\
\text { depressive symptoms, } \\
\text { improved psychological } \\
\text { resilience }\end{array}$ \\
\hline 3 & $\begin{array}{c}\text { Meng XianZe } \\
\text { [35]/ } 2012\end{array}$ & RCT & $\begin{array}{l}\text { Investigated effects of a } \\
\text { Chinese herbal formula on } \\
\text { GPS in earthquake } \\
\text { survivors with PTSD }\end{array}$ & $\begin{array}{l}\text { 12g packages of granulated } \\
\text { XTJYF or placebo twice a } \\
\text { day for eight weeks. } \\
\text { Instructed to drink the } \\
\text { contents dissolved in } \\
\text { warm, boiled water. }\end{array}$ & 268/PTSD & $\begin{array}{c}\text { Male }=71 \\
\text { Female }=174 / \mathrm{E} \\
=51.2 \& C= \\
51.0\end{array}$ & $\begin{array}{c}\text { Self-reporting } \\
\text { psychological distress }\end{array}$ & $\begin{array}{l}\text { XTJYF may be an effective } \\
\text { and safe treatment option } \\
\text { for improving GPS in } \\
\text { patients with PTSD }\end{array}$ \\
\hline 4 & $\begin{array}{c}\text { Jiang Ruifang } \\
\text { [39]/ } 2014\end{array}$ & RCT & $\begin{array}{c}\text { Test the efficacy of IPT } \\
\text { delivered by trained local } \\
\text { personnel compared with } \\
\text { TAU for PTSD and MDD } \\
\text { among adults affected by } \\
\text { the Sichuan } 2008 \\
\text { earthquake. }\end{array}$ & IPT & 49/PTSD, MDD & $\begin{array}{c}\text { Male }=35 \\
\text { Female }=14 / \mathrm{E} \\
=24.79 \& \mathrm{C}= \\
36.05\end{array}$ & CAPS \& SCID & $\begin{array}{l}\text { IPT is a promising } \\
\text { treatment for reducing } \\
\text { PTSD and depression }\end{array}$ \\
\hline 5 & $\begin{array}{c}\text { Xia Zhang } \\
{[16] / 2013}\end{array}$ & $\begin{array}{l}\text { Longitudinal } \\
\text { quasi-experimental } \\
\text { study }\end{array}$ & $\begin{array}{l}\text { Evaluated the effectiveness } \\
\text { of the NHV program }\end{array}$ & $\begin{array}{l}\text { NHV Rehabilitation } \\
\text { Services Program }\end{array}$ & 510/Disabling injuries & $\begin{array}{c}\text { Male }=179 ; \\
\text { Female }=331 / \mathrm{E} \\
=55.2: \mathrm{L}=53.4 \& \\
\mathrm{C}=51.8\end{array}$ & BI & $\begin{array}{l}\text { NHV improved the } \\
\text { long-term physical } \\
\text { functioning of Sichuan } \\
\text { earthquake survivors with } \\
\text { disabling injuries }\end{array}$ \\
\hline 6 & $\begin{array}{l}\text { Jun Ni } \\
{[17] / 2013}\end{array}$ & $\begin{array}{l}\text { Cross-sectional } \\
\text { survey }\end{array}$ & $\begin{array}{l}\text { Evaluated the effectiveness } \\
\text { of a rehabilitation } \\
\text { intervention on PDF and } \\
\text { PTSD in fractured victims } \\
\text { to identify risk factors for } \\
\text { PTSD. }\end{array}$ & Regular rehabilitation & 459/Fracture & $\begin{array}{c}\text { Male }=16 ; \\
\text { Female }= \\
296 /<30= \\
52: 30-50= \\
129: 50-70=196: \\
>70=82\end{array}$ & $\begin{array}{c}\text { PCL-C, Muscle } \\
\text { strength, ROM, } \\
\text { sensory function and } \\
\text { sit-to-stand balance } \\
\text { capacity }\end{array}$ & $\begin{array}{l}\text { PDF and PTSD were } \\
\text { significantly reduced by the } \\
\text { rehabilitation intervention }\end{array}$ \\
\hline
\end{tabular}


Table 1. Cont.

\begin{tabular}{|c|c|c|c|c|c|c|c|c|}
\hline & Author/Year & Study Design & Study Objective(s)/Aim(s) & Intervention(s) & $\begin{array}{l}\text { Participant Inclusion } \\
\text { and Type of Subject }\end{array}$ & $\begin{array}{c}\text { Subject } \\
\text { Gender/Age }\end{array}$ & $\begin{array}{c}\text { Study Outcome } \\
\text { Measurement }\end{array}$ & $\begin{array}{c}\text { Recommendations/Primary } \\
\text { Findings }\end{array}$ \\
\hline 7 & $\begin{array}{l}\text { Li Ling [20]/ } \\
\quad 2015\end{array}$ & $\begin{array}{l}\text { Prospective } \\
\text { cohort study }\end{array}$ & $\begin{array}{l}\text { Examined the development } \\
\text { and determinants of } \\
\text { long-term outcomes for } \\
\text { earthquake victims with } \\
\text { amputations }\end{array}$ & $\begin{array}{l}\text { Institution-based } \\
\text { rehabilitation }\end{array}$ & 45/Amputation & $\begin{array}{c}\text { Male }=22 \\
\text { Female }= \\
23 / \text { Age }=43.5\end{array}$ & $\begin{array}{l}\text { VAS, BI, SF-36 and } \\
\text { Life Satisfaction } \\
\text { Questionnaire-11 }\end{array}$ & $\begin{array}{c}\text { While amputees' } \\
\text { functioning and pain were } \\
\text { improved over time, QoL } \\
\text { and life satisfaction did not } \\
\text { change }\end{array}$ \\
\hline 8 & $\begin{array}{l}\text { Li Wing Sum } \\
\text { [40]/ } 2018\end{array}$ & $\begin{array}{c}\text { Cross-sectional } \\
\text { study }\end{array}$ & $\begin{array}{c}\text { Identified factors } \\
\text { associated with successful } \\
\text { functional recovery of } \\
\text { bilateral amputees' age. }\end{array}$ & $\begin{array}{l}\text { Stand Tall rehabilitation } \\
\text { programme }\end{array}$ & $\begin{array}{c}\text { 17/Traumatic bilateral } \\
\text { amputation }\end{array}$ & $\begin{array}{c}\text { Male }=8 ; \\
\text { Female }=9 / \text { Age } \\
\quad=26.59\end{array}$ & $\begin{array}{l}\text { Mobility, prosthesis } \\
\text { use and } \\
\text { health-related QoL }\end{array}$ & $\begin{array}{c}\text { Rehabilitation makes better } \\
\text { in adjustment and QoL in } \\
\text { bilateral lower limb } \\
\text { amputees }\end{array}$ \\
\hline 9 & $\begin{array}{l}\text { Li Yongqiang } \\
\text { [19]/2012 }\end{array}$ & $\begin{array}{l}\text { Non-RCT } \\
\text { clinical study }\end{array}$ & $\begin{array}{l}\text { Assessed the effect of } \\
\text { individualized physical } \\
\text { rehabilitation } \\
\text { programming on victims' } \\
\text { functional recovery. }\end{array}$ & $\begin{array}{l}\text { Physical rehabilitation } \\
\text { programming }\end{array}$ & $51 / \mathrm{SCI}$ & $\begin{array}{c}\text { Male }=21 ; \\
\text { Female }=30 / \text { age } \\
\text { ranged } 11-77 \\
\text { years }- \text { with the } \\
\text { majority of } \\
\text { persons } \\
\text { between } 18 \text { and } \\
60 \text { years of age. }\end{array}$ & $\begin{array}{c}\text { Ambulation, } \\
\text { wheelchair mobility } \\
\text { and ADL }\end{array}$ & $\begin{array}{l}\text { Earthquake victims with } \\
\text { SCI improved on physical } \\
\text { rehabilitation programme }\end{array}$ \\
\hline 10 & $\begin{array}{c}\text { Zhu } \\
\text { Zhuohong } \\
\text { [37]/ 2014 }\end{array}$ & $\begin{array}{l}\text { Non-RCT } \\
\text { clinical study }\end{array}$ & $\begin{array}{l}\text { Investigated the treatment } \\
\text { effects of calligraphy } \\
\text { therapy on child survivors } \\
\text { of Sichuan earthquakes }\end{array}$ & $\begin{array}{l}\text { Calligraphy training } 1 \text { hour } \\
\text { a day }\end{array}$ & 210/PTSD & $\begin{array}{c}\text { Boys }=105 ; \\
\text { Girls }= \\
\text { 105/children in } \\
\text { the fourth and } \\
\text { fifth grades }\end{array}$ & $\begin{array}{l}\text { PTSD, calligraphy } \\
\text { therapy, salivary } \\
\text { cortisol, salivary } \\
\text { cortisol levels and } \\
\text { arousal scores }\end{array}$ & $\begin{array}{l}\text { Successful calligraphy } \\
\text { treatment is an effective } \\
\text { and culturally congruent } \\
\text { system of intervention }\end{array}$ \\
\hline 11 & $\begin{array}{c}\text { Wang Z } \\
{[41] / 2016}\end{array}$ & $\begin{array}{l}\text { Non-RCT } \\
\text { clinical study }\end{array}$ & $\begin{array}{l}\text { Examined the use of a } \\
\text { Web-based self-help } \\
\text { intervention program and } \\
\text { investigate the relationship } \\
\text { between program use and } \\
\text { user characteristics }\end{array}$ & $\begin{array}{c}\text { A Web-based self-help } \\
\text { intervention }\end{array}$ & 146/General & $\begin{array}{c}\text { Male }=34 ; \\
\text { Female = } \\
112 / \text { Age } \\
\text { range:16-25 = } \\
30: 26-40= \\
64: 41-70=52\end{array}$ & $\begin{array}{l}\text { PDS, SCL-D, CSE, } \\
\text { CSS \& SFI }\end{array}$ & $\begin{array}{l}\text { Both individual (e.g. } \\
\text { demographic, health } \\
\text { problems, psychological) } \\
\text { and social factors (e.g. } \\
\text { social functioning, social } \\
\text { support) should be } \\
\text { considered when } \\
\text { delivering Web-based } \\
\text { interventions }\end{array}$ \\
\hline
\end{tabular}

Notes: CBT: cognitive-behavioral therapy; NET: narrative exposure therapy; XTJYF: Xiao-Tan-Jie-Yu-Fang; GPS: General Psychological Status; IPT: Interpersonal Psychotherapy; TAU:

Treatment As Usual; MDD: Major Depressive Disorder; PTSD: Posttraumatic Stress Disorder; CAPS: Clinician Administered PTSD Scale; SCID: Structured Clinical Interview for DSM-IV;

NHV:N = non-governmental organizations (NGOs), local health departments (H), and professional rehabilitation volunteers (V); BI: Barthel Index; PDF: Physical Dysfunction; PCL-C: The

PTSD Checklist-Civilian Version; ROM: Joint Range of Motion; VAS: Visual Analogue Scale; ABCF: Activity-Based Cognitive Fear Reduction; FSSC: Fear Survey Schedule for Children;

PDS: Posttraumatic Diagnostic Scale; SCL-D: Symptom Checklist 90-Depression; CSE: Trauma Coping Self-Efficacy Scale; CSS: Crisis Support Scale; QoL: Quality of Life; and SFI: Social

Functioning Impairment. 


\subsection{Characteristics of Participants}

The identified studies predominantly investigated the victims who were diagnosed with PTSD $(n=6)$ [35-39,41], followed by limb amputees $(n=2)$ [20,40]. In other studies, the participants included those with SCI $(n=1)$ [19], fractures $(n=1)$ [17] and general disabling injuries $(n=1)$ [16]. Although all of the 11 studies enrolled their samples of participants from the survivors of the 2008 Wenchuan earthquake, only seven of them $(n=7)[16,17,19,20,35,36,39]$ reported the specific locations where they were recruited from, and particularly included the most severely affected counties or cities of Beichuan, Mianzhu, Dujiangyan and Jiangyo. Other participants were recruited from outside of the earthquake zone and mainly from the hospitals where they were receiving various kinds of treatment, such as West China Hospital - Chengdu, Sichuan Provincial People's Hospital, the Shifang Counseling Center and Shifang People's Hospital. All of these hospitals are located in Sichuan province, southwest of PRC.

\subsection{Mean Age and Gender}

The mean age of participants in each study ranged from 10.5 [37] to 55.7 [36] years. Apart from the two studies $(n=2)$ which directly dwelt on children, adolescents or youths [37,38], seven studies $(n=7)$ reported the age range of participants to be, on average, between 16 and 85 years $[17,19,20,35,36,40,41]$, while other studies did not report any age ranges. All of the 11 studies involved the participants of both genders (sexes), whereby $63.4 \%$ of all of the total participants were females, and the highest number of them was reported to be 296 [17].

\subsection{Study Designs}

A combination of qualitative and quantitative methodologies based on the cross-sectional approach was used in the 11 studies and included case-control, retrospective and prospective cohort, questionnaire or interview survey, and longitudinal quasi-experimental designs. Data were directly obtained from the populations (subjects) investigated using different data collection tools. Of 11 studies, a randomized control trial (RCT) was employed in four studies $(n=4)[35,36,38,39]$, where different participants were randomly allocated to either intervention or non-intervention groups, in order to receive different HRR interventions. Almost all of the studies were designed and championed by academic-based institutions and mainly by the universities, although with financial support from the various funding stakeholders like the Chinese government, charities and foundations, as well as the support from volunteers like hospital staff for data collection.

\subsection{Interventions and Settings}

Apart from the three studies $(n=3)$ where regular physical rehabilitation was used, other studies were blended with a different mode of rehabilitation interventions which included narrative Exposure Therapy (NET), cognitive-behavioral therapy (CBT), Xiao-Tan-Jie-Yu-Fang (XTJYF)—a Chinese herbal formula, Interpersonal Psychotherapy (IPT), NHV rehabilitation programming, Stand Tall rehabilitation, calligraphic training and Web-based self-help rehabilitation programs. While the Stand Tall rehabilitation intervention was jointly delivered at the clinic, school and home [40], the rest of interventions were exclusively delivered in the hospitals $[16,19,20,40]$ or community-based settings $[17,35,36,39,41]$ and followed by the schools [37,38]. The delivery of some interventions like CBT [38] was group-based, on the other hand. The shortest and longest delivery times for some of HRR interventions identified in the studies were 30 days and 5 years, for calligraphic training [37] and institution-based rehabilitation [20], respectively. In this case, there was no particular timeframe specified or recommended for the identified interventions.

\subsection{HRR Outcomes}

Analysis of the 11 studies showed that many of them $(n=6)$ intended to assess PTSD or major depressive disorder (MDD) [35-39,41] as the primary outcome(s) for HRR, while others explored the 
physical functioning and QoL of participants. Among the most prevalent symptoms to have aroused PTSD or MDD, as revealed in six studies, were anxiety and depression, general mental stress, anger and interpersonal violence, and other mental disorders. Accordingly, there was both a variation in and a combination of the different tools used to measure these outcomes. They included the Impact of Event Scale-Revised (IES-R) [36], the Children's Revised Impact of Event Scale (CRIES-13) [37,38], the Center for Epidemiologic Studies Depression Scale (CES-D), the Connor-Davidson Resilience Scale (CD-RISC) [38], the Symptom Checklist-90-Revised (SCL-90-R) [35], the Clinician-Administered PTSD Scale (CAPS), the PTSD diagnosis and Structured Clinical Interview for DSM-IV (SCID) for MDD diagnosis [39], and the PTSD Checklist-Civilian Version (PCL-C) [17]. Others were the Barthel Index (BI) $[16,19,20]$, the Visual Analogue Scale (VAS), the Medical Outcomes Study Short-Form 36 (SF-36) [20], the Amputee mobility predictor (AMP) (AMPPro version) [40], the Checklist 90-Depression (SCL-D), the Trauma Coping Self-Efficacy scale (CSE), the Crisis Support Scale (CSS) and the Social Functioning Impairment questionnaire (SFI) [41]. Based on these outcome measurement tools, CRIES-13 and BI were applied in more than two studies.

\subsection{Quality Assessment and the Risk of Bias}

Figure 2 and Table 2 summarize the different aspects concerning the methodological quality of the studies based on the Cochrane Risk of Bias Assessment Tool [33] and ROBINS-I [34]. Among the RCT studies (Figure 2), most of the methodological aspects were not well-covered. Four $(n=4)$ out of seven aspects of the Cochrane Collaboration's risk of bias tool were covered in one study [36]. 'Selective reporting' was the only aspect covered by all four of the RCT studies. On the side of non-randomized studies (Table 2), the domains of ROBINS-I for assessing different types of bias were considered in at least five studies $(\mathrm{n}=5)$; and their overall bias rating was 'moderate' $[16,17,19,37,41]$. The overall biases for the other two studies were rated as critical $(n=1)$ [20] and serious $(n=1)$ [40].

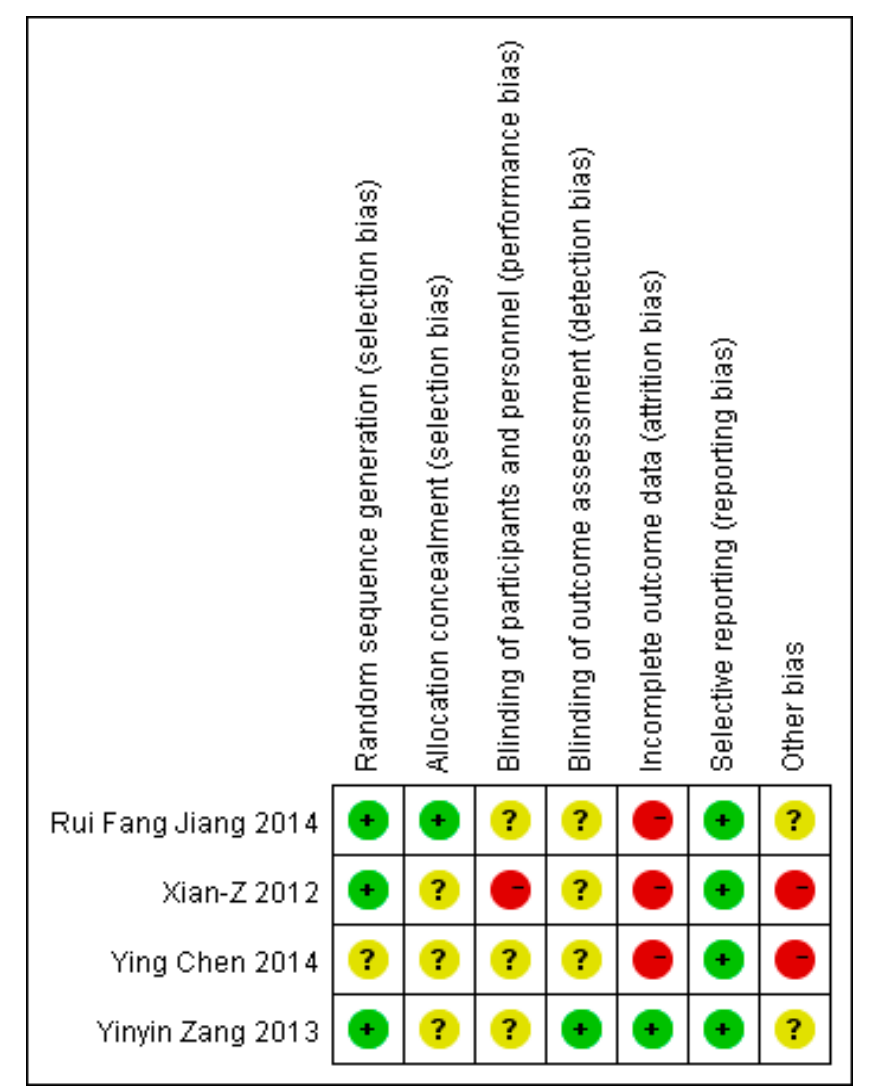

Figure 2. Quality assessment of the randomized controlled trial (RCT) studies that were included in the review based on the Cochrane Collaboration's risk of bias tool. 
Table 2. Quality assessment of the non-RCT studies based on ROBINS-I.

\begin{tabular}{|c|c|c|c|c|c|c|c|c|c|}
\hline & Author(s)/Year & $\begin{array}{l}\text { Bias Due to } \\
\text { Confounding }\end{array}$ & $\begin{array}{l}\text { Bias in Selection of } \\
\text { Participants into } \\
\text { the Study }\end{array}$ & $\begin{array}{c}\text { Bias in } \\
\text { Measurement of } \\
\text { Intervention(s) }\end{array}$ & $\begin{array}{l}\text { Bias Due to Departures } \\
\text { from Intended } \\
\text { Intervention(s) }\end{array}$ & $\begin{array}{l}\text { Bias Due to } \\
\text { Missing Data }\end{array}$ & $\begin{array}{c}\text { Bias in } \\
\text { Measurement of } \\
\text { Outcome(s) }\end{array}$ & $\begin{array}{l}\text { Bias in Selection } \\
\text { of Reported } \\
\text { Result(s) }\end{array}$ & $\begin{array}{l}\text { Overall } \\
\text { Bias }\end{array}$ \\
\hline 1 & $\begin{array}{l}\text { Li Yongqiang/ } \\
2012\end{array}$ & Low & Moderate & Low & Low & Moderate & Moderate & Low & Moderate \\
\hline 2 & Xia Zhang/ 2013 & Low & Moderate & Low & Moderate & Moderate & Moderate & Low & Moderate \\
\hline 3 & Jun Ni/ 2013 & Moderate & Moderate & Low & Moderate & Low & Moderate & Low & Moderate \\
\hline 4 & $\begin{array}{c}\text { Zhu Zhuohong/ } \\
2014\end{array}$ & Low & Low & Moderate & Moderate & Low & Moderate & Low & Moderate \\
\hline 5 & Li Ling/ 2015 & Serious & Moderate & Serious & No information & Critical & Low & Low & Critical \\
\hline 6 & Wang Z/ 2016 & Moderate & Moderate & Moderate & No information & Low & Moderate & Low & Moderate \\
\hline 7 & $\begin{array}{l}\text { Li Wing Sum/ } \\
2019\end{array}$ & Moderate & Serious & Moderate & Low & Low & Moderate & Low & Serious \\
\hline
\end{tabular}




\section{Discussion}

This retrospective systematic review provides an insight into the HRR programs that have been rendered to the survivors of the 2008 Wenchuan earthquake over the past ten years, based on 11 studies. Its findings, however, indicate that there is still a paucity of research with robust methodological designs on HRR. This aside, the study highlights that large-scale earthquakes, like the 2008 Wenchuan earthquake, impact and expose the survivors of different ages—-from adults to children — to a wide range of health conditions, not limited only to the risks of long-lasting or permanent disabilities emanating from injuries like SCI, fractures, TBI and peripheral nerve injuries $[16,17,19,20,40]$. In this case, rehabilitation-which is also a critical component of healthcare systems delineating different strategies for health care, prevention, cure, trauma management and support $[26,28,42]$ —is vital in responding to the immediate and long-term health needs of causalities after an earthquake. Rehabilitation is particularly vital for addressing PTSD—which the majority of the included studies identified in our systematic review show to have affected many survivors. PTSD is a psychological disorder caused by unusual threats or catastrophic events such as earthquakes $[12,14,15,43]$. It can also occur in people who have experienced, witnessed or known about traumatic events that posed to them a risk of death, serious harm or threat to physical integrity, and that as a response to such have felt intense fear, helplessness or horror [44]. Thus, various rehabilitation interventions were warranted in the prevention of the loss of function, the restoration of function and the increase or maintenance of current function $[22,23,45]$, not only for the over 374,000 individuals injured in the 2008 Wenchuan earthquake [6,9], but also for PTSD victims. Rehabilitation is essential for the psychological status of earthquake survivors by improving their wellness, QoL and their performance of ADL, as well as for promoting their social inclusion and participation in community life [22,26]. Also, rehabilitation in disasters and emergencies can help to decrease morbidity and mortality, for instance, that related to suicide attempts, and reduce the length of hospital stays [46,47]. Despite the 11 studies included in our systematic review being heterogeneous-in terms of objectives, target populations, settings, outcomes, methodological designs and durations for implementation-they all reaffirmed an overarching role of rehabilitation in the post-earthquake scenario.

Given the large-scale nature of the 2008 Wenchuan earthquake, there was indeed a great need for several rehabilitation interventions to be enacted, considering the diversity of the characteristics of the survivors. This can be explained by the 11 studies, which reported participants of varying HRR needs and outcomes such as functioning, mobility, QoL and psychology [16,19,36-41] —all of which required either immediate, intensive or long-term rehabilitation of a given duration and at aiven location. To a large extent, the interventions reported in 11 studies are heterogeneous and they aimed at addressing the physical, behavioral, psychological, self-management and educational HRR needs of the survivors of the 2008 Wenchuan earthquake. Apart from physical rehabilitation or therapeutic programs, which were dominant, other interventions including NET, CBT, IPT, Stand Tall rehabilitation and calligraphic training were also implemented and reported to be effective in helping the survivors of the 2008 Wenchuan earthquake, especially in improving their functional and QoL outcomes, as well as their abilities to perform ADLs more independently $[16,17,19,20,40]$. The interventions were also effective in treating and reducing the survivors' PTSD symptoms like anxiety and depression, and also in enhancing their psychological resilience $[35,36,38,39]$. These findings are consistent with previous results from a broad systematic literature review and meta-analysis studies that similarly explored the different rehabilitation interventions, services and outcomes in post-earthquake settings, and those following other disasters within and outside China [2,13-15,43,44,48-52]. Encouragingly, some of the HRR programs after the 2008 Wenchuan earthquake, such as physical and physiological rehabilitation, commenced within the first 5 months after the earthquake, which is commendable and helped to ameliorate long-term impacts such as injuries and PTSD from turning into acute problems for survivors that would prevent them from returning to normal life.

Ideally, any rehabilitation interventions or programs in situations following earthquakes and other disaster situations must be multidimensional-taking into account the different models of treatment 
that identify not only the health and physical needs, but also lead to better outcomes for patients. Fortunately, apart from the commonly known rehabilitation interventions, especially the physical and physiological therapies, our systematic review discovered other unique rehabilitation approaches to have been used in rehabilitating the survivors of the 2008 Wenchuan earthquake. They were premised on traditional or indigenous treatments and digital technologies, such as traditional Chinese medicine -XTJYF [35] and web-based interventions [41]. In this case, embracing the traditional rehabilitation treatments was not only helpful in terms of cheaper fees, easy accessibility and enabling the provision of quick services, especially in the resource-constrained settings, but also helped treatment to be embraced in settings like Sichuan province, where traditional medicine is still cherished for good health and treating various symptoms of patients [52-54]. Moreover, similar to XTJYF traditional Chinese medicine, for example, 'Kampo', a Japanese medicine is reported from ancient times to have been used to treat various infections and traumas, injuries, fractures and pain [52]. On the other hand, harnessing the evolving digital technologies, for example, different web-based applications, can be a pathway for delivering a full spectrum of health services, including self-rehabilitation $[28,55]$ without the need for face-to-face encounters between a patient and a rehabilitation service provider in the post-earthquake scenario. Of note, based on our findings, no specific locations were designated or recommended in the 11 studies for the delivery of the above interventions. Rather, different interventions or programs were rendered to victims at the clinic, or in schools, homes, hospitals or community-based settings. What matters, in this regard, is the identification of a convenient and suitable place that is preferred by the patient; guaranteeing his/her confidentiality, privacy and safety; and above all, not compromising the recommended healthcare standards $[23,25,28]$.

Earthquakes, like any other disasters, are traumatic events and they result in a range of physical, mental and psychological health consequences $[2,8,12-15,43,50-52,56]$. Indeed, this is attested to in the results of six studies in our systematic review [35-39,41] — which showed a high prevalence of PTSD among the different groups of survivors of the 2008 Wenchuan earthquake. PTSD aroused several symptoms such as anxiety, depression, anger, stress, psychoticism, somatization, sleep disorders, interpersonal sensitivity and violence, as well as thoughts, feelings, or stimuli associated with the traumatic events, among victims [2,12-15,35-39,41,44,51,52,56,57]. Again, this argument concurs with the findings of an earlier systematic review and meta-analysis studies, which affirmed how a real burden of PTSD is prevalent in many earthquake survivors [12-15,43,44,49,56,58]. The studies described PTSD as one the most frequent and debilitating psychological impacts associated with high magnitude earthquakes, in addition to other public health challenges like fatalities, injuries, disabilities and disease outbreaks $[2,5,8,11]$. This reinforces the importance of prioritizing PTSD among the targets of the physical and mental health needs in the post-earthquake scenario to support not only the survivors, but also other persons who are involved in the relief process, including the health-care workers themselves [10]. Understanding the symptoms and patterns of PTSD or MDD in detail may help to find better prevention strategies, develop methods of rapidly assessing the needs of affected and traumatized people and elucidate how to provide their necessary rehabilitation. In one way or another, this can be possible with the help of using various rehabilitation assessment tools like those identified in some studies included in our systematic review, for instance, PCL-C [17], CAPS and MDD diagnosis [39], and SCL-D and CSE [41]. These tools are fundamental in detecting, diagnosing and treating the early symptoms of PTSD before they become acute or chronic among the victims of earthquakes and other disasters. However, the use of such tools should comply with the WHO ICD-10 Classification [56] and also take into account the precarious and widespread economic, social and cultural impacts of earthquakes [2,6,8-11], if they are to effectively address the PTSD-related reactions of victims, especially in the early post-earthquake period.

Another pertinent consideration for HRR in the post-earthquake scenario is the need to promote and strengthen the interventions that target specific groups of people within the general community affected-which may be more vulnerable and at greater risk of negative outcomes than others [50]. The most vulnerable groups in disasters and emergencies are identified to include physically or mentally 
disabled persons (blind, with cognitive disorders or with mobility limitations), elderly persons, women, children, adolescents, ethnic minorities, prisoners, homeless persons, illiterate persons and the economically impoverished $[2,10,14,28,50,51]$. These groups corroborate with examples that our systematic review identified in some of the included studies, such as the females who were exposed to a higher risk of PTSD [17], illiterate amputees [20], childhood survivors, those with hyperarousal symptoms [37] and the adolescents who lost their parents [38]. It is worth noting that the proportions of elderly (over 65 years) and younger ( $<15$ years) patients are reported to have been $18.2 \%$ and $11.2 \%$ of the total, respectively, after the 2008 Wenchuan Earthquake [4]. It is quite clear that earthquakes and other mega disasters overwhelm available resources like health-care, medicine, personnel and infrastructure, as well as rehabilitation services, especially in the less-resourced settings [28,45-47]. This can lead to the disregarding of the special needs of some vulnerable groups, like mobility and hearing aids, daily medications and special or preferred food diets, especially in the response phase. As a result, this can aggravate health-related effects and other risks among the victims, such as PTSD and MDD, isolation and loneliness, drug or alcohol abuse, loss of dignity and sense of guilt, doubt, distress and intense fear, vertigo, insomnia, psychoses or even suicidal ideation [15,50]. Besides, negative outcomes from some rehabilitation interventions can be achieved if the needs of vulnerable groups are not adequately addressed. Evidence in this regard is revealed in one study in our systematic review that found no change in the QoL and life satisfaction among the illiterate survivors with amputation [20]. From the HRR standpoint, the needs for the most vulnerable groups during and in the aftermath of earthquakes must be quickly identified by different service providers while rendering rehabilitation care. This helps not only to enhance their functional, and psychological self-care, wellbeing, QoL and adaptive capacity, but also their sense of social belongingness and connectivity, being loved and sympathy from others. Moreover, the level of vulnerability of some groups at greater risk may not only predict and determine the usage of, adherence to and coping with, but also the success of implementing certain rehabilitation programs.

By and large, due to the diversity of health needs and disabling conditions associated with earthquakes, identifying effective rehabilitation interventions or programs and their implementation becomes a challenge at times. One possible solution is to deliver some interventions in groups using RCTs, through which people are allocated 'at random' to receive one of several interventions [59]. An RCT is required to detect uncertainty and small-to-moderate, but clinically meaningful, treatment effects between competing interventions. It is of little wonder that the rehabilitation programs implemented through RCTs in the four studies included in our systematic review were reported to be effective with significant outcomes, particularly in the treatment groups $[35,36,38,39]$. The findings in similar studies conducted previously also confirmed the efficacy of rehabilitation treatment through RCTs $[44,57,58]$. However, RCTs may not be feasible for complex rehabilitation programs under certain circumstances of large-scale earthquakes with large populations affected. It is important that non-RCT designs other than experimental, retrospective and cohort approaches identified in our systematic review be carefully considered while selecting the different rehabilitation interventions for earthquake-affected survivors, for achieving optimal and better outcomes. Of note, the successful implementation of interventions-whether based on RCT or non-RCT—requires intersectoral collaboration among different service providers, and where possible, designating some responsibilities [22,60]. In this regard, although most of the HRR interventions identified in the 11 studies were championed by academic-based authors, they were coordinated in one way or another with other stakeholders such as the Chinese government, charities, foundations, hospital staff and other volunteers-whose roles mainly related to the funding and data collection. This notwithstanding, our systematic review found that there was no consensus among stakeholders in the 11 studies on the specific interventions or even the unified tools for assessing the HRR needs of survivors. A similar case was echoed in a systematic review by Hong and Efferth (2016) [15], where no particular tool for assessing PTSD among 2008 Wenchuan earthquake survivors was agreed upon by the different studies included in it. 


\section{Study Limitations}

Generally speaking, HRR in post-earthquake scenarios and other disasters can be diverse. Thus, some eligible and relevant studies may have been excluded, as a result narrowing the scope and the findings of our systematic review, given that the study time was restricted to between 2008 and 2018, only five English databases were searched, and only papers published in English were considered. However, excluding the papers published in languages (and mainly Chinese) other than English was inevitable, as much as our initial intention was to search and review both English and Chinese studies, since the latter consisted of various inconsistencies and particularly poor methodological designs. Additionally, as noted above, our study was retrospective and focused on the 10th anniversary of the 2008 Wenchuan earthquake, and as such, some recent studies published beyond 2018 may have been left out. Aside from these limitations, our systematic review provides an overview of some of the HRR interventions that have been rendered to the survivors of the 2008 Wenchuan earthquake.

\section{Conclusions}

Based on the 11 studies included in our systematic review, different HRR interventions for the survivors or victims of the 2008 Wenchuan earthquake, although being predominated by physical rehabilitation, were reported to be effective. However, it is inconclusive as to which specific intervention(s) and tool(s) was/were much more effective than others for rehabilitating the survivors of the earthquake. One explanation for this is the heterogeneity of the 11 studies-they are without a consensus, since each had different objectives, participants, outcomes, designs and implementations of the intervention. What ought to be noted instead, particularly in the post-earthquake scenario, is that rendering some specific HRR may be complex, and achieving better outcomes requires tailoring the interventions used based on components. They should not be limited only to different models of rehabilitation treatment, but also the collaboration between different services providers, patients' needs and consent, existing rehabilitation capacity and other resources-above all, premising them on the existing global rehabilitation standards. Besides, the rehabilitation needs of the vulnerable groups and populations at greater risk must be quickly identified and prioritized. Although over ten years have passed since the occurrence of the 2008 Great Wenchuan earthquake, its devastating impacts continue to reverberate in the minds of survivors, which calls for their continuous rehabilitation care. Therefore, the rehabilitation interventions adopted need to be accurately assessed over a given time to be effective, and this can be achieved by conducting more robust research that employs appropriate methodological designs and augments our systematic review.

Author Contributions: Conceptualization: J.K.B.; methodology: J.K.B., X.Z. and C.C.; formal analysis: J.K.B. and X.Z.; writing —original draft preparation: J.K.B.; writing—review and editing: J.K.B. and X.Z. All authors have read and agreed to the published version of the manuscript.

Funding: This research is funded by Sichuan University.

Conflicts of Interest: The authors declare no conflict of interest.

\section{References}

1. Sim, T.; Jun, L.Y. Natural Hazards Governance in China. In Oxford Research Encyclopedia of Natural Hazard Science; Oxford University Press: New York, NY, USA, 2018. [CrossRef]

2. Chan, E.Y.Y.; Gao, Y.; Griffiths, M.S. Literature review of health impact post-earthquakes in China 1906-2007. J. Public Health 2009, 32, 52-61. [CrossRef]

3. Wang, C.; Wu, J.; He, X.; Ye, M.; Liu, W.; Tang, R. Emerging Trends and New Developments in Disaster Research after the 2008 Wenchuan Earthquake. Int. J. Environ. Res. Public Health 2019, 16, 29. [CrossRef] [PubMed]

4. Yang, J.; Chen, J.; Liu, H.; Zheng, J. Comparison of two large earthquakes in China: The 2008 Sichuan Wenchuan Earthquake and the 2013 Sichuan Lushan Earthquake. Nat. Hazards 2014, 73, 1127-1136. [CrossRef] 
5. Han, W.; Liang, C.; Jiang, B.; Ma, W.; Zhang, Y. Major Natural Disasters in China, 1985-2014: Occurrence and Damages. Int. J. Environ. Res. Public Health 2016, 13, 1118. [CrossRef] [PubMed]

6. Guha-Sapir, D. The Emergency Events Database in The Emergency Events Database EM-DAT; Universite Catholique de Louvain (UCL), CRED: Brussels, Belgium, 2019.

7. Zhou, Y.; Liu, Y.; Wu, W.; Li, N. Integrated risk assessment of multi-hazards in China. Nat. Hazards 2015, 78, 257-280. [CrossRef]

8. Balikuddembe, J.K.; Sinclair, P. Uganda at Glance of 5.7 Magnitude Earthquake: Lessons for Earthquake Risk Reduction. PLoS Curr. 2018, 10. [CrossRef]

9. Lu-Ping, Z.; Manuel Rodriguez-Llanes, M.J.; Qi, W.; van den Oever, B.; Westman, L.; Albela, M.; Liang, P.; Gao, C.; De-Sheng, Z.; Hughes, M.; et al. Multiple injuries after earthquakes: A retrospective analysis on 1,871 injured patients from the 2008 Wenchuan earthquake. Crit. Care 2012, 16, R87. [CrossRef]

10. Chan, E.Y. The untold stories of the Sichuan earthquake. Lancet 2008, 372, 359-362. [CrossRef]

11. Tang, B.; Chen, Q.; Chen, X.; Glik, D.; Liu, X.; Liu, Y.; Zhang, L. Earthquake-related injuries among survivors: A systematic review and quantitative synthesis of the literature. Int. J. Disaster Risk Reduct. 2017, 21, 159-167. [CrossRef]

12. Dai, W.; Chen, L.; Lai, Z.; Li, Y.; Wang, J.; Liu, A. The incidence of post-traumatic stress disorder among survivors after earthquakes:a systematic review and meta-analysis. BMC Psychiatry 2016, 16, 188. [CrossRef]

13. Beaglehole, B.; Mulder, R.T.; Boden, J.M.; Bell, C.J. A systematic review of the psychological impacts of the Canterbury earthquakes on mental health. Aust. N. Z. J. Public Health 2019, 43, 274-280. [CrossRef] [PubMed]

14. Yiming, L.; Jin, C.; Ruzek, J.I.; Zhengkui, L. Posttraumatic stress disorder following the 2008 Wenchuan earthquake: A 10-year systematic review among highly exposed populations in China. J. Affect. Disord. 2019, 243, 327-339.

15. Hong, C.; Efferth, T. Systematic Review on Post-Traumatic Stress Disorder Among Survivors of the Wenchuan Earthquake. Trauma Violence Abus. 2016, 17, 542-561. [CrossRef] [PubMed]

16. Zhang, X.; Reinhardt, J.D.; Gosney, J.E.; Li, J. The NHV Rehabilitation Services Program Improves Long-Term Physical Functioning in Survivors of the 2008 Sichuan Earthquake: A Longitudinal Quasi Experiment. PLoS ONE 2013, 8, e53995. [CrossRef]

17. Ni, J.; Reinhardt, D.J.; Zhang, X.; Xiao, M.; Ling, L.; Jin, H.; Zeng, X.; Jianan, L. Dysfunction and Post-Traumatic Stress Disorder in Fracture Victims 50 Months after the Sichuan Earthquake. PLoS ONE 2013, 8, e77535. [CrossRef]

18. Jones, C.E.; Faas, A.J. Social Network Analysis Focused on Individuals Facing Hazards and Disasters. In Social Network Analysis of Disaster Response, Recovery, and Adaptation; Jones, C.E., Faas, A.J., Eds.; Butterworth-Heineman (Elsevier): Kidlington, Oxford, UK, 2017.

19. Li, Y.; Reinhardt, J.D.; Gosney, J.E.; Zhang, X.; Hu, X.; Chen, S.; Ding, M.; Li, J. Evaluation of functional outcomes of physical rehabilitation and medical complications in spinal cord injury victims of the Sichuan earthquake. J. Rehabil. Med. 2012, 44, 534-540. [CrossRef]

20. Li, L.; Reinhardt, J.D.; Zhang, X.; Pennycott, A.; Zhao, Z.; Zeng, X.; Li, J. Physical function, pain, quality of life and life satisfaction of amputees from the 2008 Sichuan earthquake: A prospective cohort study. J. Rehabil. Med. 2015, 47, 466-471. [CrossRef]

21. Alexander, D. Disability and disaster: An Overview. In Disability and Disaster; Kelman, I., Stough, L.M., Eds.; Palgrave Macmillan: London, UK, 2015; pp. 384-394.

22. World Health Organization (WHO). World Report on Disability; WHO: Geneva, Switzerland, 2011.

23. World Health Organization (WHO). Concept Paper: WHO Guidelines on Health-Related Rehabilitation (Rehabilitation Guidelines); WHO: Geneva, Switzerland, 2012.

24. United Nations (UN). Universal Declaration of Human Rights; UN: New York, NY, USA, 1948.

25. World Health Organization (WHO). Rehabilitation 2030: A Call for Action; WHO: Geneva, Switzerland, 2017.

26. World Health Organization (WHO). WHO). WHO Global Disability Action Plan 2014-2021. In Better Health for All People With Disabilities; WHO: Geneva, Switzerland, 2015.

27. United Nations (UN). United Nations Convention on the Rights of People with Disabilities (UNCRD); UN: New York, NY, USA, 2008.

28. Balikuddembe, K.J.; Reinhardt, D.J. Can Digitization of Healthcare help Low-Resourced Countries Provide Better Community-Based Rehabilitation Services? Phys. Ther. 2019, 100, 217-224. 
29. United Nations International Strategy for Disaster Reduction (UNISDR). Sendai Framework for Disaster Risk Reduction 2015-2030; The United Nations Office for Disaster Risk Reduction: Geneva, Switzerland, 2015.

30. Moher, D.; Liberati, A.; Tetzlaff, J.; Altman, D.G.; PRISMA Group. Preferred reporting items for systematic reviews and meta-analyses: The PRISMA statement. Ann. Intern. Med. 2009, 511, 264-269. [CrossRef]

31. Sayers, A. Tips and tricks in performing a systematic review. Br. J. Gen. Pract. 2007, 57, 999. [CrossRef]

32. Eriksen, B.M.; Frandsen, F.T. The impact of patient, intervention, comparison, outcome (PICO) as a search strategy tool on literature search quality: A systematic review. J. Med Libr. Assoc. 2018, 106, 420-431. [CrossRef] [PubMed]

33. Higgins, J.P.; Altman, D.G.; Gøtzsche, P.C.; Jüni, P.; Moher, D.; Oxman, A.D.; Savovic, J.; Schulz, K.F.; Weeks, L.; Sterne, J.A. Cochrane Bias Methods Group; Cochrane Statistical Methods Group. The Cochrane Collaboration's tool for assessing risk of bias in randomised trials. BMJ 2011, 343, d5928. [CrossRef] [PubMed]

34. Sterne, J.A.; Hernán, A.M.; Higgins, J.P.; Reeves, B.C.; Savović, J.; Berkman, D.N.; Viswanathan, M.; Henry, D.; Altman, D.G.; Ansari, T.M.; et al. ROBINS-I: A tool for assessing risk of bias in non-randomised studies of interventions. BMJ 2016, 355, i4919. [CrossRef] [PubMed]

35. Meng, X.Z.; Wu, F.; Wei, K.P.; Xiu, J.L.; Shi, J.; Pang, B.; Sun, D.Z.; Qin, F.Z.; Huang, Y.; Lao, L. A Chinese Herbal Formula to Improve General Psychological Status in Posttraumatic Stress Disorder: A Randomized Placebo-Controlled Trial on Sichuan Earthquake Survivors. Evid. Based Complement Altern. Med. 2012, 2012, 691258. [CrossRef]

36. Zang, Y.; Hunt, N.; Cox, T. A randomized controlled pilot study: The effectiveness of narrative exposure therapy with adult survivors of the Sichuan earthquake. BMC Psychiatry 2013, 13, 41. [CrossRef]

37. Zhu, Z.; Wang, R.; Kao, H.S.; Zong, Y.; Liu, Z.; Tang, S.; Xu, M.; Liu, I.C.; Lam, S.P. Effect of calligraphy training on hyperarousal symptoms for childhood survivors of the 2008 China earthquakes. Neuropsychiatr. Dis. Treat. 2014, 10, 977-985.

38. Chen, Y.; Shen, W.W.; Gao, K.; Lam, C.S.; Chang, W.C.; Deng, H. Effectiveness RCT of a CBT Intervention for Youths Who Lost Parents in the Sichuan, China, Earthquake. Phychiatric Serv. 2014, 2, 259-262. [CrossRef]

39. Jiang, R.F.; Tong, H.Q.; Delucchi, K.L.; Neylan, T.C.; Shi, Q.; Meffert, S.M. Interpersonal psychotherapy versus treatment as usual for PTSD and depression among Sichuan earthquake survivors: A randomized clinical trial. Confl. Health 2014, 8, 14. [CrossRef]

40. Li, W.S.; Chan, S.Y.; Chau, W.W.; Law, S.W.; Chan, K.M. Mobility, prosthesis use and health-related quality of life of bilateral lower limb amputees from the 2008 Sichuan earthquake. Prosthet. Orthot. Int. 2019, 43, 104-111. [CrossRef]

41. Wang, Z.; Wang, J.; Maercker, A. Program Use and Outcome Change in a Web-Based Trauma Intervention: Individual and Social Factors. J. Med. Internet Res. 2016, 18, e243. [CrossRef]

42. Stucki, G.; Cieza, A.; Melvin, J. The International Classification of Functioning, Disability and Health: A unifying model for the conceptual description of the rehabilitation strategy. J. Rehabil. Med. 2007, 39, 279-285. [CrossRef] [PubMed]

43. Neria, Y.; Nandi, A.; Galea, S. Post-traumatic stress disorder following disasters: A systematic review. Psychol. Med. 2008, 38, 467-480. [CrossRef] [PubMed]

44. Lopes, A.P.; Macedo, T.F.; Coutinho, E.S.F.; Figueira, I.; Ventura, P.R. Systematic Review of the Efficacy of Cognitive-Behavior Therapy Related Treatments for Victims of Natural Disasters: A Worldwide Problem. PLoS ONE 2014, 9, e109013. [CrossRef] [PubMed]

45. Von Groote, P.; Bickenbach, J.; Gutenbrunner, C. The world report on disability-Implications, perspectives and opportunities for physical and rehabilitation medicine (PRM). J. Rehabil. Med. 2011, 43, 869-875. [CrossRef] [PubMed]

46. Rathore, F.A.; Gosney, J.E.; Reinhardt, J.D.; Haig, A.J.; Li, J. Medical Rehabilitation After Natural Disasters: Why, When, and How? Arch. Phys. Med. Rehabil. 2012, 93, 1875-1881. [CrossRef] [PubMed]

47. Gosney, J. Physical Medicine and Rehabilitation: Critical Role in Disaster Response. Disaster Med. Public Health Prep. 2010, 4, 110-112. [CrossRef]

48. Ghasem, M.; Ardalan, A.; Hamidreza, K.; Mohammad, K.; Abba, O. Physical Rehabilitation Services in Disasters and Emergencies: A Systematic Review. Iran. J. Public Health 2019, 48, 808-815.

49. Khan, F.; Amatya, B.; Gosney, J.; Rathore, F.A.; Burkle, F.M., Jr. Medical Rehabilitation in Natural Disasters: A Systematic Review. Arch. Phys. Med. Rehabil. 2015, 96, 1709-1727. [CrossRef] 
50. Sheikhbardsiri, H.; Yarmohammadian, M.H.; Rezaei, F.; Maracy, M.R. Rehabilitation of vulnerable groups in emergencies and disasters: A systematic review. World J. Emerg. Med. 2017, 8, 253-263. [CrossRef]

51. Parker, G.; Lie, D.; Siskind, J.D.; Martin-Khan, M.; Raphael, B.; Crompton, D.; Kisely, S. Mental health implications for older adults after natural disasters-A systematic review and meta-analysis. Int. Psychogeriatr. 2016, 28, 11-20. [CrossRef]

52. Takayama, S.; Kaneko, S.; Numata, T.; Kamiya, T.; Arita, R.; Saito, N.; Kikuchi, A.; Ohsawa, M.; Kohayagawa, Y.; Ishii, T. Literature Review: Herbal Medicine Treatment after Large-Scale Disasters. Am. J Chin. Med. 2017, 45, 1345-1364. [CrossRef] [PubMed]

53. Osei, F.; Omoniyi, M.; Boateng, A.K. Clinical and Traditional Rehabilitation Approaches on Injured Football Athletes in Ashanti Region. Ital. J. Sports Rehabil. Posturol. 2015, 2, 242-253.

54. Dunning, K.N.; Zhao, M.; Haley, R. Physical therapy in China: Entwining cultural practices. Rehab. Manag. 2009, 22, 28-29.

55. Nussbaum, R.; Kelly, C.; Quinby, E.; Mac, A.; Parmanto, B.; Dicianno, B.E. Systematic Review of Mobile Health Applications in Rehabilitation. Arch. Phys. Med. Rehabil. 2019, 100, 115-127. [CrossRef] [PubMed]

56. Soldatos, C.R.; Paparrigopoulos, T.J.; Pappa, D.A.; Christodoulou, G.N. Early post-traumatic stress disorder in relation to acute stress reaction: An ICD-10 study among help seekers following an earthquake. Psychiatry Res. 2006, 143, 245-253. [CrossRef]

57. Rintala, A.; Päivärinne, V.; Hakala, S.; Paltamaa, J.; Heinonen, A.; Karvanen, J.; Sjögren, T. Effectiveness of Technology-Based Distance Physical Rehabilitation Interventions for Improving Physical Functioning in Stroke: A Systematic Review and Meta-analysis of Randomized Controlled Trials. Arch. Phys. Med. Rehabil. 2019, 100, 1339-1358. [CrossRef]

58. García-Rudolph, A.; Laxe, S.; Saurí, J.; Opisso, E.; Tormos, J.M.; Bernabeu, M. Evidence of chronic stroke rehabilitation interventions in activities and participation outcomes: Systematic review of meta-analyses of randomized controlled trials. Eur. J. Phys. Rehabil. Med. 2019. [CrossRef]

59. Alejandro, R.J.; Murray, W.E. (Eds.) Randomized Controlled Trials: Questions, Answers, and Musings; BMJ Books; John Wiley \& Sons: Hoboken, NJ, USA, 2007; Volume 2, p. 160.

60. Gosney, J.; O'Connell, C. Rehabilitation of Disaster Casualties. In Disaster Medicine: Comprehensive Principles and Practices, 2nd ed.; Koenig, K., Schultz, C., Eds.; Cambridge University Press: Cambridge, MA, USA, 2016; pp. 377-388.

(C) 2020 by the authors. Licensee MDPI, Basel, Switzerland. This article is an open access article distributed under the terms and conditions of the Creative Commons Attribution (CC BY) license (http://creativecommons.org/licenses/by/4.0/). 